\title{
Reasons for Contraceptive Nonuse among Women Having Unmet Need for Contraception in Developing Countries
}

\author{
Gilda Sedgh and Rubina Hussain
}

\begin{abstract}
The level of unmet need for contraception-an important motivator of international family planning programs and policies-has declined only slightly in recent decades. This study draws upon data from 51 surveys conducted between 2006 and 2013 in Africa, Asia, and Latin America and the Caribbean to provide an updated review of the reasons why many married women having unmet need are not practicing contraception. We examine the reasons for contraceptive nonuse and how these reasons vary across countries and according to national levels of unmet need and contraceptive use. We present specific findings regarding the most widespread reasons for nonuse, particularly infrequent sex and concerns regarding side effects or health risks. Our findings suggest that access to services that provide a range of methods from which to choose, and information and counseling to help women select and effectively use an appropriate method, can be critical in helping women having unmet need overcome obstacles to contraceptive use. (STUdIES IN FAMILY PLANNING 2014; 45[2]: 151-169)
\end{abstract}

$\mathrm{F}$ or decades, the concept of unmet need for contraception has been integral to international family planning policy, programs, and research. The importance of this concept has increased over time because of its relevance to landmark events, including the 1994 International Conference on Population and Development, the establishment of the United Nations Millennium Development Goals (MDGs), and the London Summit on Family Planning. A thorough review of the research on unmet need undertaken in 2000 strongly indicated that a focus on satisfaction of unmet need for contraception would enable family planning programs to help women and couples fulfill their individual aspirations while increasing contraceptive prevalence (Casterline and Sinding 2000).

Despite this recognition of the importance of addressing unmet need, the level of unmet need for contraception in developing countries has declined only slightly in recent decades (Alkema et al. 2013; Darroch, Singh, and Ashford 2013). An estimated 222 million women have unmet need for modern contraception in the developing world (Singh and Darroch 2012), and this number may increase in the decades ahead if the pace of contraceptive up- 
take does not keep pace with population growth and the growing demand for smaller families and precisely timed births (Darroch, Sedgh, and Ball 2011). Estimates also indicate that if all women having unmet need used a modern contraceptive method, 54 million unintended pregnancies and 26 million abortions would be averted each year (Singh and Darroch 2012).

Studies of the reasons for unmet need, based on surveys of married women in the late 1980s and early 1990s, found that lack of knowledge about contraception was highly prevalent, particularly in sub-Saharan Africa, and that concerns regarding side effects and health risks were common, especially in Asia and Latin America (Bongaarts and Bruce 1995; Westoff and Bankole 1995). More recently, a review of surveys of women in developing countries having unmet need in 1995-2005 indicated that lack of knowledge about contraception had declined substantially and that concerns regarding the side effects and health risks associated with modern contraceptive methods were increasingly common among reasons for nonuse of a method, as were infrequent sexual activity and breastfeeding (Sedgh et al. 2007). ${ }^{1}$

Many qualitative studies examining barriers to contraceptive use have also been undertaken. Although these studies have been limited in geographic scope, reviews of them have identified key themes. A review of studies of young women, primarily unmarried women in sub-Saharan Africa, identified lack of access to family planning education and to information concerning how contraceptive methods work as underlying themes across the studies (Williamson et al. 2009). Concerns regarding side effects and health risks pertained especially to menstrual disruption and fears of infertility. Unmarried women were also unwilling to risk the social disapproval associated with seeking services.

A broader review of relevant literature regarding barriers to contraceptive use identified obstacles such as limited method choice, misinformation concerning methods, constraints on women's decisionmaking abilities, health concerns, and provider biases (Campbell, SahinHodoglugil, and Potts 2006). A number of landmark studies found these reasons for nonuse as well, and also indicated that women having unmet need might be less strongly motivated to avoid pregnancy than are those who practice contraception (Casterline, Perez, and Biddlecom 1997; Stash 1999; Casterline, Sathar, and ul Haque 2001).

Qualitative studies have largely uncovered many of the same general barriers identified by the large-scale quantitative surveys, albeit with more explanatory detail. Whereas the available qualitative research enhances our understanding of the barriers faced by certain populations of women, a geographically broad, quantitative assessment of women's reasons for nonuse can help shed light on general patterns and trends regarding the relative importance of these reasons. This study provides an updated review of the reasons why married women having unmet need are not practicing contraception in the major developing regions and subregions of the world and in each of the countries for which data are available. We also examine how these reasons vary across countries, according to levels of unmet need and contraceptive use. Finally, we explore evidence related to three key reasons for nonuse-infrequent sex, concerns regarding side effects and health risks, and postpartum amenorrhea/breastfeeding -in an effort to better understand the experiences of women who cite them.

1 Women who cited lactational amenorrhea (LAM) as a method of contraception were not counted among women with unmet need. 


\section{DATA AND METHODS}

To identify current levels of and reasons for unmet need for contraception, we draw upon data from Demographic and Health Surveys (DHSs) conducted in 51 countries in Africa, Asia, and Latin America and the Caribbean ${ }^{2}$ since 2006. ${ }^{3}$ These countries represent 68 percent of the population in the developing world, excluding Eastern Asia. Unmet need for contraception is estimated to be lower in Eastern Asia than in any other subregion of the world (Alkema et al. 2013), and Demographic and Health surveys have not been conducted there. These analyses are limited to married women because some national surveys do not include unmarried women in their samples and some do not ask unmarried women about sexual activity and therefore do not ascertain the level of unmet need or reasons for contraceptive nonuse in this population.

\section{Measure of Unmet Need for Contraception}

We use the definition of unmet need for contraception for married women that was developed for application to the Demographic and Health Surveys and recently revised to ensure greater consistency in estimation across countries and surveys (Bradley et al. 2012). According to this definition, married women of reproductive age (aged 15-49 years) have unmet need if they are fecund, do not want a child in the next two years or at all, and are not using any method of contraception, either modern or traditional. Pregnant women and women experiencing postpartum amenorrhea (and who gave birth within two years prior to the survey) are classified as having unmet need if they indicated that their current or recent pregnancy was unintended.

\section{Reasons for Nonuse of Contraceptives}

Married women who were not using any method of contraception and who had indicated that they did not want to have a child in the near future were asked to indicate their reasons for nonuse. The question took the general form: "You have said that you do not want a child soon/another child soon/any children/any more children, but you are not using any method to avoid pregnancy. Can you tell me why?" Women having unmet need who were pregnant at the time of the survey, who had indicated they were not sure whether they want to have a child, or who said they were not sure when they want to have a child, were not asked their reasons for nonuse. Among the reasons we examined were those pertaining to access, opposition to contraception, breastfeeding, sexual activity, and concerns regarding the side effects and health risks of methods.

\section{Analytic Approach}

For each country, we present the proportion of married women having unmet need for a contraceptive method. Women having unmet need were allowed to provide more than one reason for not using a method. We present the proportion of women who cite each of several key reasons for contraceptive nonuse.

2 We employ the United Nations classification of countries into world regions and subregions. This classification combines Latin America and the Caribbean into one region.

3 We classify surveys on the basis of the year in which they ended. 
We computed the average levels of unmet need and of specific reasons for contraceptive nonuse for each of the three developing regions from which DHS data are available. We also produced these estimates for each of the subregions for which surveys represent at least 50 percent of all women of reproductive age. The 51 surveys conducted since 2006 that contain information regarding unmet need represent 74 percent, 75 percent, and 19 percent of the populations of women aged 15-49 in Africa, Asia, and Latin America and the Caribbean, respectively (see Table 1). The estimates for Latin America and the Caribbean should not be interpreted as regionally representative. The data represent greater than 50 percent of the populations of women aged 15-49 in the subregions of Eastern, Middle, and Western Africa and South-Central and South-Eastern Asia. Although the Latin America and Caribbean region is poorly represented at both the regional and subregional levels (particularly in Central America), 49 percent of women in the Caribbean and 24 percent of women in South America are represented by the surveys.

The computed regional and subregional average levels of unmet need and reasons for nonuse are weighted averages of the findings for countries in each region. The 2012 population of married, 15-49-year-old women in each country served as the weights. These population sizes were estimated by applying the survey-based estimates of the proportion of 15-49-yearold women who are married to the number of women estimated to be in this age group by the UN Population Division (UN 2013a). For countries in which surveys did not yield estimates of the percent of women who are married (i.e., surveys that did not include unmarried women), the estimated proportion of 15-49-year-old women who are married was taken from the UN's world marriage data (UN 2013b).

We also classified countries according to their level of unmet need for contraception and examined whether the prevalence of key reasons for nonuse varied across four groups of countries: those where unmet need is low, low/medium, medium/high, and high. Similarly, we examined whether reasons for nonuse varied across four groups of countries classified by contraceptive prevalence. Chi-square tests were used to identify reasons that varied significantly in prevalence across these groups of countries.

TABLE 1 Number of countries and percentage of women aged 15-49 sampled in selected surveys containing data regarding unmet need, by region and subregion, 51 developing countries, 2006-13

\begin{tabular}{lrr}
\hline Region and subregion & $\begin{array}{r}\text { Number of countries } \\
\text { represented by surveys }\end{array}$ & $\begin{array}{r}\text { Percentage of women aged 15-49 } \\
\text { represented by surveys }\end{array}$ \\
\hline Latin America and Caribbean & 7 & 19.0 \\
Caribbean & 2 & 48.7 \\
Central America & 1 & 4.6 \\
South America & 4 & 24.3 \\
Asia & 13 & 74.7 \\
South-Central Asia & 6 & 89.5 \\
South-Eastern Asia & 4 & 57.1 \\
Western Asia & 3 & 8.7 \\
Africa & 31 & 73.7 \\
Eastern Africa & 11 & 90.6 \\
Middle Africa & 5 & 71.5 \\
Northern Africa & 1 & 37.8 \\
Southern Africa & 3 & 9.0 \\
Western Africa & 11 & 95.9 \\
\hline a Excludes Eastern Asia because data were not available for any of the countries in this subregion.
\end{tabular}


Last, to look more closely at the experiences of women who gave some of the key reasons for nonuse, we used cross-tabulations to compute (1) the proportion of women who had sex in the previous three months among women citing infrequent or no sex as their reason for nonuse and among women giving any other reason for nonuse, and (2) the proportion of women who had ever used a modern contraceptive method ${ }^{4}$ among those citing concerns regarding side effects and health risks and among women giving any other reason for nonuse. We computed the proportion of women who had given birth within the prior six months and reported elsewhere in the survey that they were amenorrheic, among those citing postpartum amenorrhea or breastfeeding as their reason for nonuse.

\section{RESULTS}

\section{Regional Estimates of Unmet Need for Contraception}

As shown in Table 2, 24 percent of married women in Africa and 15 percent in Asia (excluding Eastern Asia) have unmet need for contraception. On average, 13 percent have unmet need in Latin America and the Caribbean, but coverage of this region by the surveys is very limited. Of the five subregions for which averages could be computed, unmet need is highest in Eastern and Middle Africa (26 percent in both).

\section{Country Estimates of Unmet Need}

The percentage of women having unmet need varies widely across countries. The level of unmet need in Latin America and the Caribbean ranges from 9 percent in Colombia to 35 percent in Haiti. Unmet need in Asia ranges from 11 percent in Indonesia to 32 percent in Timor-Leste. In Africa, unmet need is lowest in Egypt (12 percent) and highest in Sao Tome and Principe (38 percent) and in Ghana and Liberia (36 percent each). In nearly two-thirds of the countries in Africa, the level of unmet need exceeds 25 percent.

\section{Regional Estimates of Reasons for Nonuse among Women Having Unmet Need}

Though women are asked to indicate all of their reasons for not practicing contraception, the average number of responses proffered is 1.2. Across the countries, most women who give more than one reason give only two reasons, and in most instances the second reason is classified as "other." Thus, some barriers to use might be more common than indicated here, because women might have cited only one of the key barriers even when multiple barriers existed.

On average, 34 percent of women in Latin America and the Caribbean, 31 percent of women in Asia, and 19 percent of women in Africa say they are not using a method because they have sex infrequently or not at all (see Table 2 and Figure 1). At the subregional level, this reason is most frequently given in South-Central Asia (32 percent). This reason is least common in Eastern and Western Africa (15 percent and 16 percent, respectively).

4 In 24 countries, ascertaining whether women had ever used any method (modern or traditional) was possible but not whether they had ever used a modern method. 


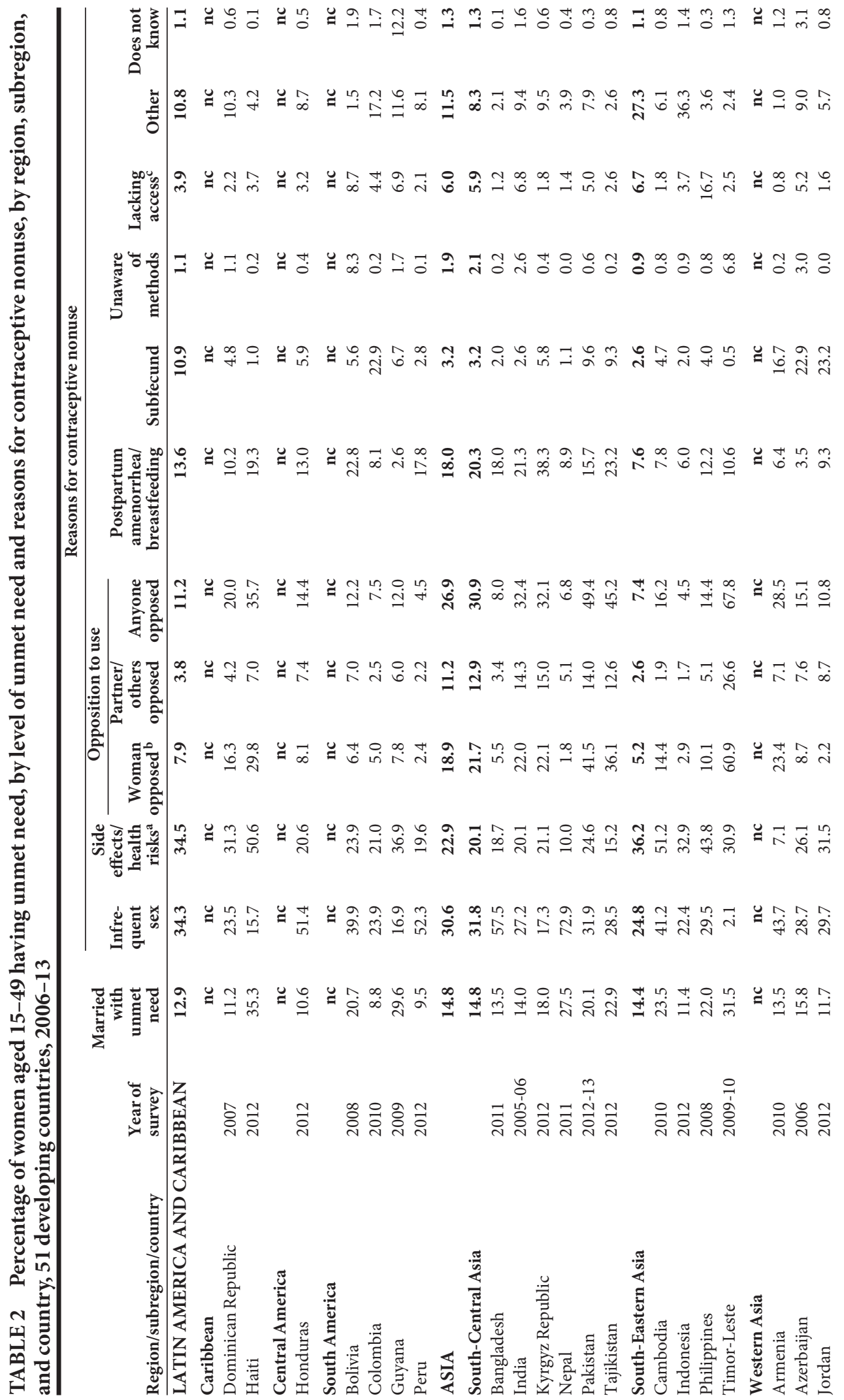




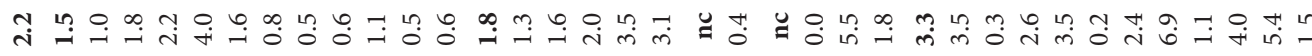

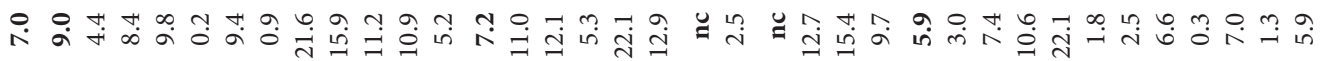

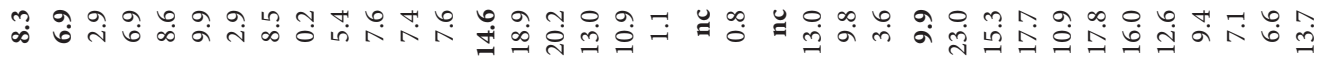

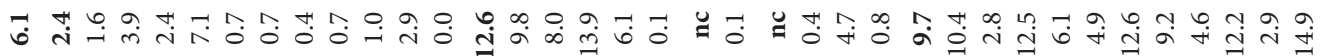
m

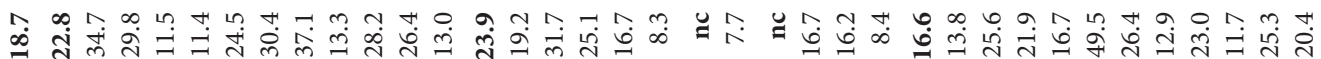
年 菅

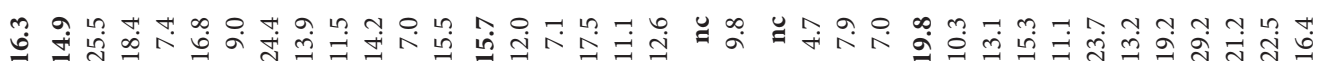

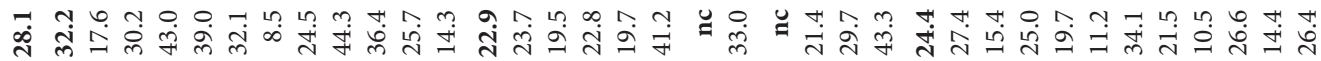
పே

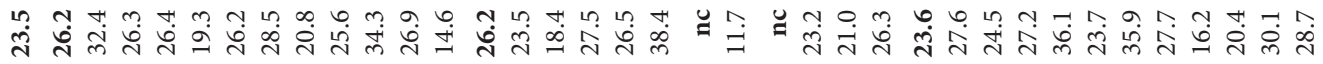

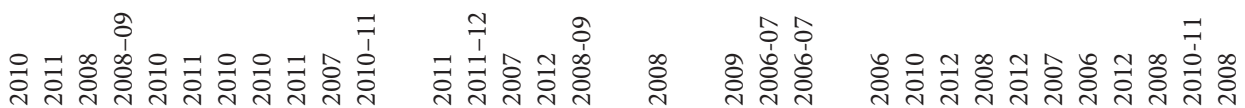

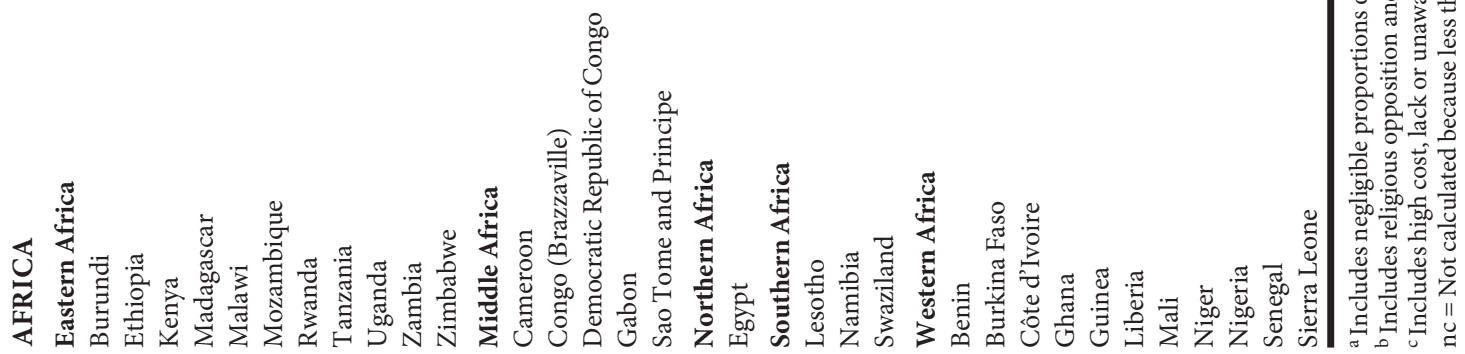


FIGURE 1 Prevalence of married women aged 15-49 citing key reasons for nonuse of contraception, by region, 2006-13

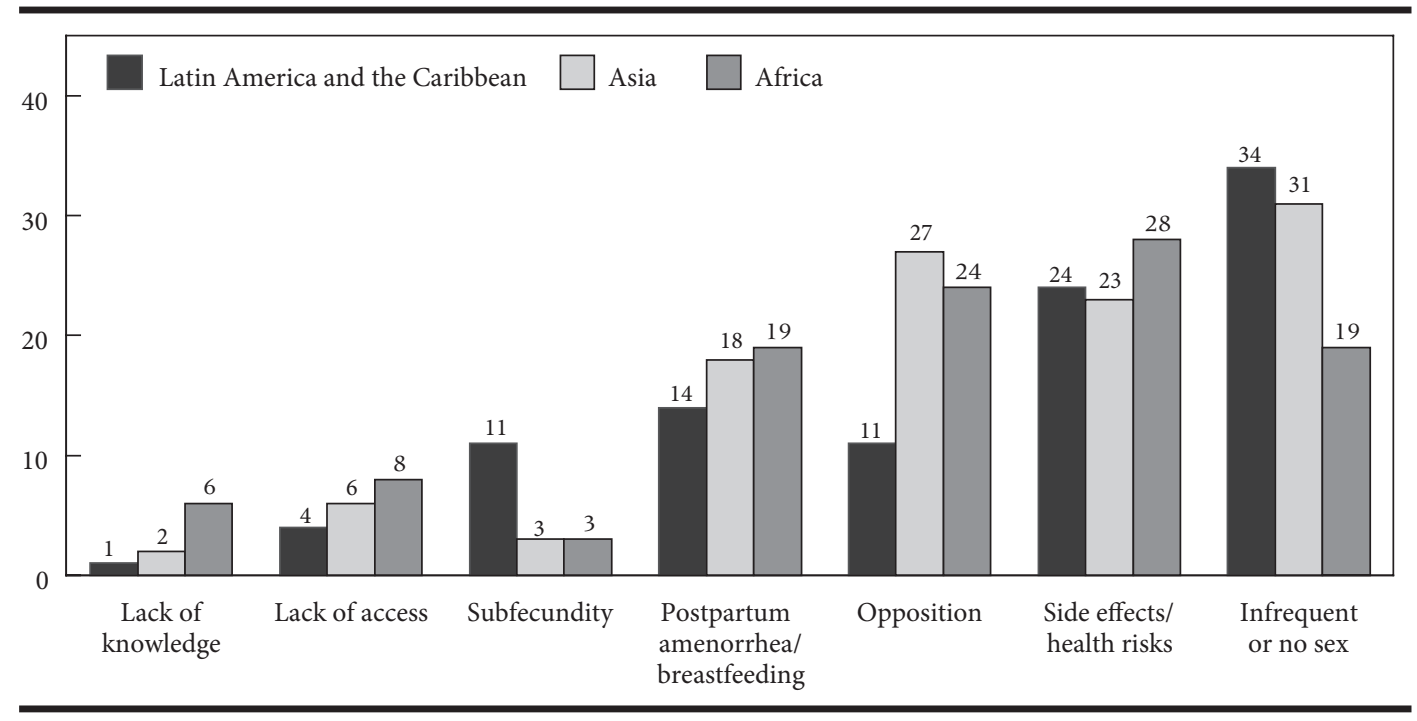

Roughly 35 percent of women in Latin America and the Caribbean, 28 percent of women in Africa, and 23 percent of women in Asia are not practicing contraception because they are concerned about the side effects and health risks of methods, or they find the methods inconvenient to use. (Inconvenience of methods is cited by a small minority of women whose reasons fall under this general category.) These reasons are especially prevalent in South-Eastern Asia (36 percent) and Eastern Africa (32 percent). They are least common in South-Central Asia, where 20 percent of women nevertheless cite this reason.

Only 11 percent of women in Latin America and the Caribbean indicate that they, their partner, or someone else close to them is opposed to the practice of contraception, whereas 25 percent and 27 percent of women in Africa and Asia, respectively, cite opposition. Opposition to the practice of contraception is most frequently cited in South-Central Asia (31 percent) and Western Africa (30 percent), and is least prevalent in South-Eastern Asia (7 percent). Postpartum amenorrhea and breastfeeding are also fairly common reasons for nonuse, cited by 14-19 percent of women across the three regions. Some 11 percent of women in Latin America and the Caribbean say they believe they cannot become pregnant, as do 3 percent in Africa and Asia.

On average, only 4-8 percent of women in the three regions say they lack access to or could not afford contraception, ${ }^{5}$ and 1-6 percent say they are unaware of methods. In Middle Africa, however, 15 percent cite lack of access and 13 percent cite lack of knowledge, and in Western Africa, 10 percent cite each of these reasons.

\section{Country Estimates of Key Reasons for Nonuse}

Regional averages can mask important cross-country variations in the prevalence of reasons for contraceptive nonuse. An exceptionally large proportion of married women having un-

5 Included in this group are women who say that they do not know a source of services, the source is too far away, their preferred method is not available or no method is available, or they cannot afford contraception. 
met need in Nepal (73 percent) and Bangladesh (58 percent) indicate that they are not using a method because they have sex infrequently or are not having sex at all (see Table 2 and Figure 2). Concern regarding side effects and health risks is most common in Haiti and Cambodia (51 percent), and is cited by at least one-third of women in 13 countries. Opposition to contraception is highest in Timor-Leste (68 percent) and Pakistan (49 percent). In nearly all countries, women are more likely to cite their own opposition to contraception than the opposition of their partner or another individual.

At least one-fourth of women cite postpartum amenorrhea or breastfeeding as a key reason for nonuse in 13 African countries. Lack of access appears negligible in most countries but is more than two times as prevalent in the Philippines (17 percent) as in any other Asian country. Lack of access is also very prevalent in Benin (23 percent), Congo (Brazzaville) (20 percent), and Cameroon, Côte d'Ivoire, and Guinea (18-19 percent), and is cited by more than 10 percent of women in another ten African countries. Awareness of contraception seems nearly universal, but 10-15 percent of women in Benin, Cameroon, Côte d'Ivoire, Democratic Republic of Congo, Liberia, Nigeria, and Sierra Leone indicate that they are not aware of methods.

\section{Reasons for Nonuse by Level of Unmet Need and Contraceptive Prevalence}

Opposition to contraception is significantly more common-and concerns regarding side effects and health risks are moderately significantly more common-in countries having high levels of unmet need than in countries having the lowest levels of unmet need (see Table 3). These reasons are cited by 30 percent and 33 percent, respectively, of respondents in the nine countries where at least 30 percent of women have unmet need for contraception, but by only 14 percent and 24 percent, respectively, of women in the ten countries where fewer than 15 percent of women have unmet need. Infrequent sex is inversely associated with level of unmet need, cited by only 14 percent of women in countries having high unmet need and 37 percent of women in countries having low unmet need. The prevalence of access barriers does not vary significantly with the level of unmet need.

Of the nine countries having the highest level of unmet need, six are in Africa (see Table 2 ). To explore whether the observed associations are a function of regional differences in the prevalence of key reasons for nonuse, we limited the same analysis to the 31 countries in Africa. The same directions of association were observed, though only the inverse association between unmet need and infrequent sex was significant (not shown). The number of countries represented by surveys in Asia and Latin America and the Caribbean is not sufficient for region-specific analysis.

The prevalence of infrequent sex (including sexual inactivity) as a reason for nonuse is greater in countries having high contraceptive prevalence (Table 3). Opposition, access barriers, and postpartum amenorrhea and/or breastfeeding are significantly less likely to be stated as a reason for nonuse in high prevalence countries than in low prevalence countries. The prevalence of concern regarding side effects and health risks is similar in countries having high and low contraceptive prevalence.

In every country, women who cite infrequent sex are significantly less likely to report having had sex in the three months prior to the survey, compared with women who give other rea- 
FIGURE 2 Proportion of women citing key reasons for nonuse, by country, 2006-13

a. Unaware of methods

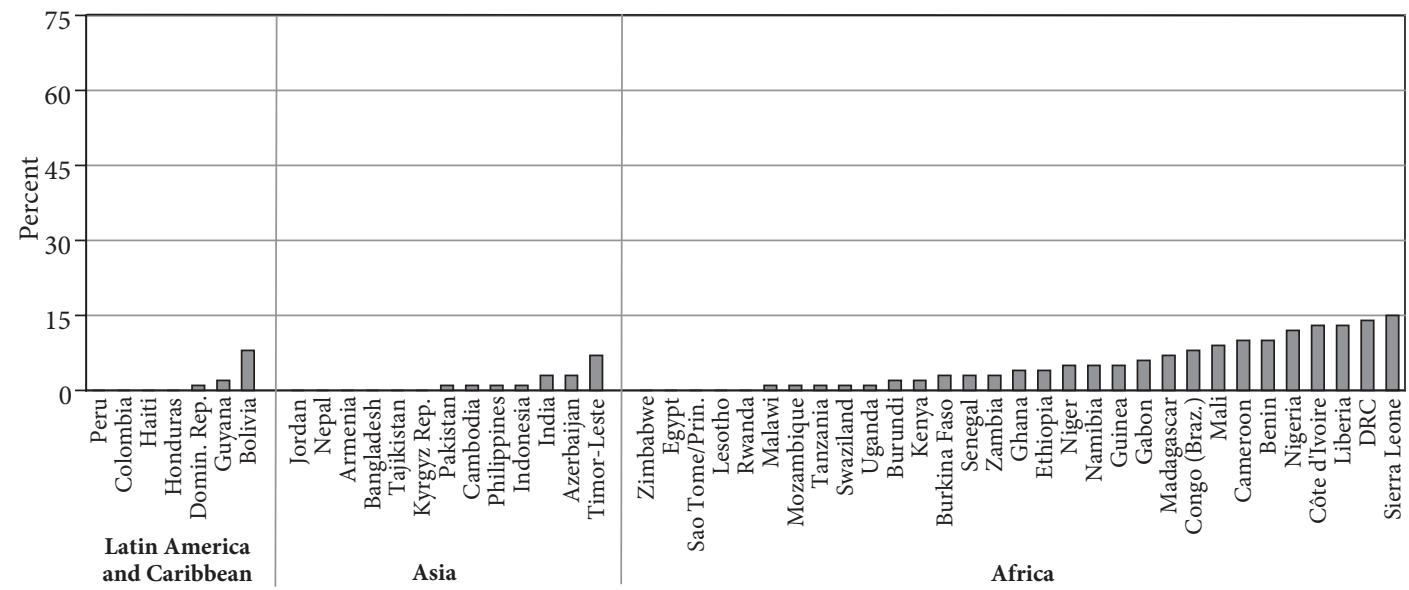

b. Lack of access

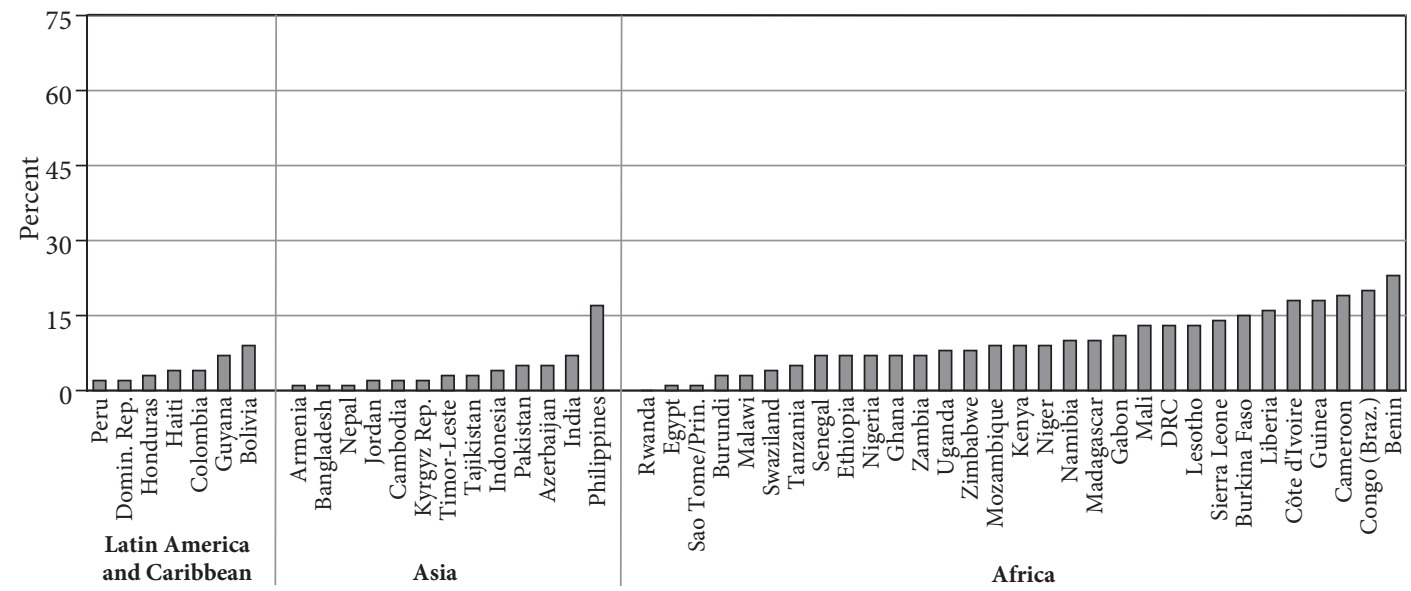

c. Opposition

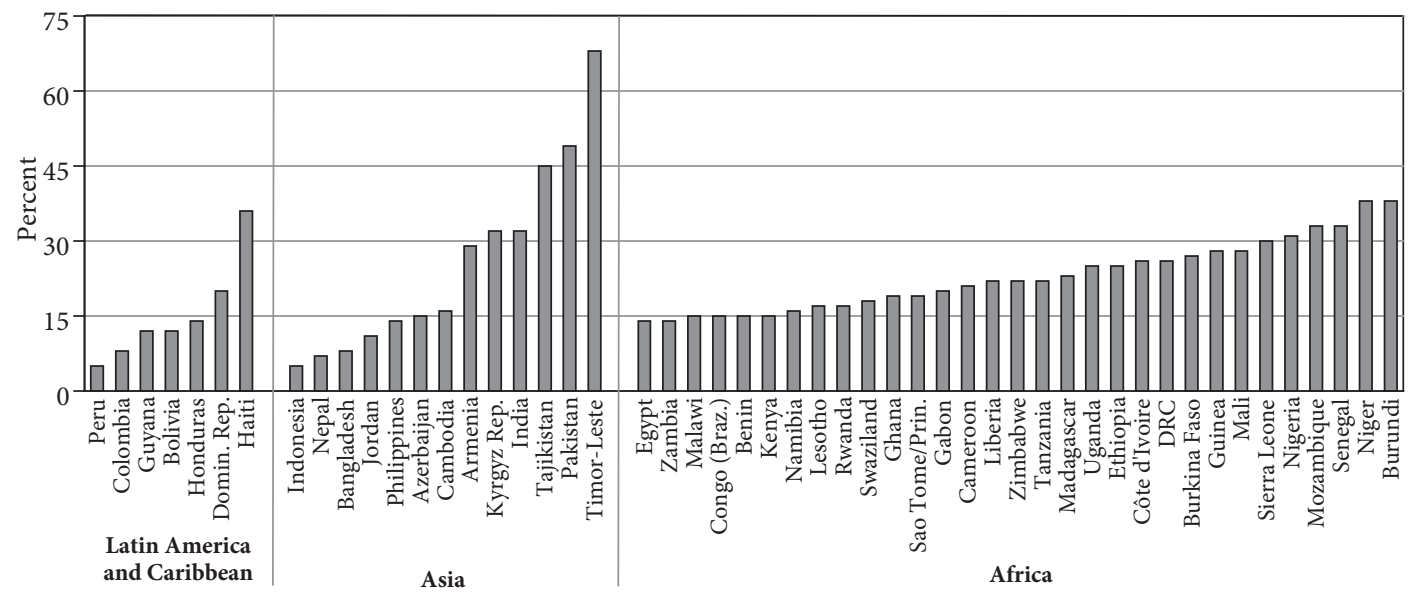


FIGURE 2 (continued)

\section{d. Postpartum amenorrhea or breastfeeding}

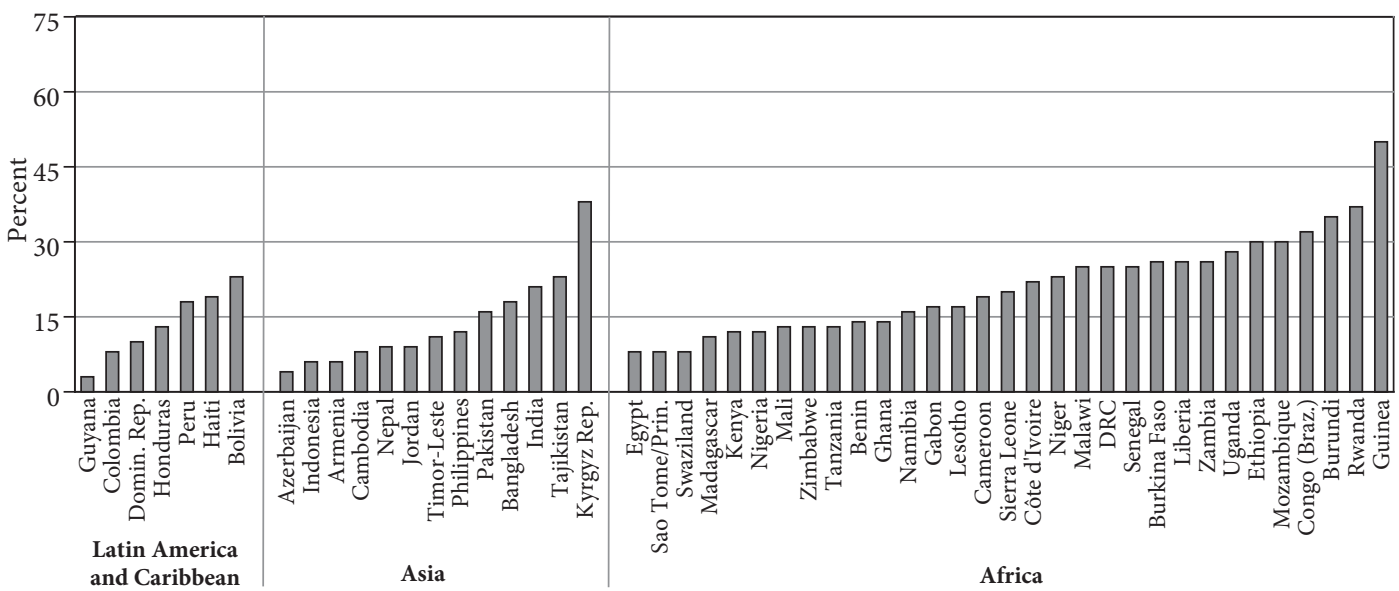

\section{e. Infrequent or no sex}

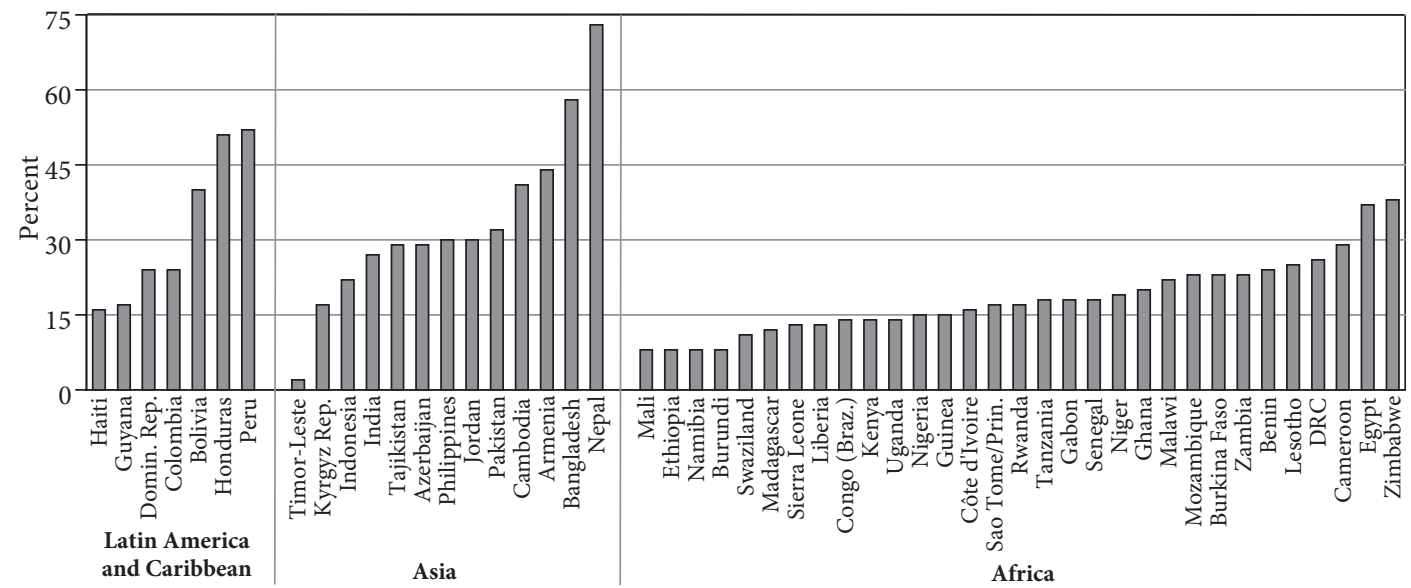

f. Concerns about health risks or side effects

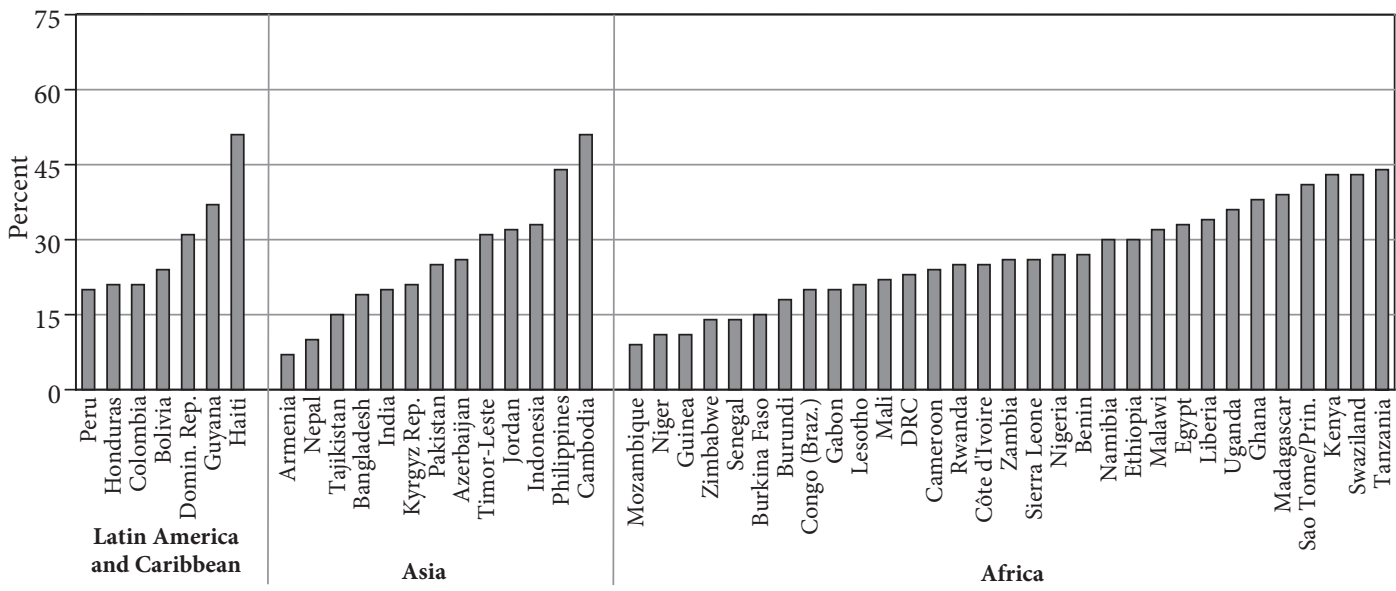

Congo (Braz.) = Congo (Brazzaville). DRC $=$ Democratic Republic of Congo. Domin. Rep. $=$ Dominican Republic. Kyrgyz Rep. $=$ Kyrgyz Republic. Sao Tome/Prin. = Sao Tome and Principe. 
TABLE 3 Percentage of women aged 15-49, by level of unmet need and contraceptive prevalence, according to reason for nonuse, 51 developing countries, 2006-13

\begin{tabular}{|c|c|c|c|c|c|c|}
\hline & $\begin{array}{r}\text { Number of } \\
\text { countries } \\
(\mathrm{n}=51)\end{array}$ & $\begin{array}{r}\text { Lack of } \\
\text { access/ } \\
\text { high cost }\end{array}$ & $\begin{array}{r}\text { Woman or } \\
\text { other person } \\
\text { opposed }\end{array}$ & $\begin{array}{r}\text { Postpartum } \\
\text { amenorrhea/ } \\
\text { breastfeeding }\end{array}$ & $\begin{array}{r}\text { Infrequent } \\
\text { or no sex }\end{array}$ & $\begin{array}{r}\text { Concern about } \\
\text { side effects/ } \\
\text { health risks }\end{array}$ \\
\hline Level of unmet need (percent) & & & * & & $* * *$ & \\
\hline$<15$ & 10 & 2.7 & 14.4 & 11.8 & 36.9 & 23.6 \\
\hline $15-24$ & 17 & 9.2 & 24.2 & 20.8 & 24.1 & 25.1 \\
\hline $25-29$ & 15 & 10.1 & 21.4 & 19.3 & 21.1 & 26.4 \\
\hline$\geq 30$ & 9 & 6.1 & 30.2 & 18.8 & 14.0 & 33.4 \\
\hline Contraceptive prevalence & & & $* * *$ & $* * *$ & ** & $* *$ \\
\hline$<20$ & 11 & 13.4 & 28.3 & 23.7 & 16.9 & 20.1 \\
\hline $20-39$ & 14 & 3.4 & 31.8 & 21.1 & 18.1 & 29.7 \\
\hline $40-59$ & 17 & 7.2 & 17.4 & 15.3 & 26.1 & 28.7 \\
\hline$\geq 60$ & 9 & 3.1 & 10.6 & 12.5 & 37.5 & 25.8 \\
\hline
\end{tabular}

${ }^{*}$ Chi-square test for linear trend significant at $\mathrm{p} \leq 0.05 ;{ }^{* *} \mathrm{p} \leq 0.01 ;{ }^{* * *} \mathrm{p} \leq 0.001$.

${ }^{a}$ Marginally significant at $\mathrm{p}=0.06$.

sons for nonuse (see Table 4). In 21 of the 50 countries for which data are available, however, at least half of the women who mention infrequent sex as a reason for nonuse report having sex in the three months prior to the survey.

Women who express concerns regarding side effects and health risks associated with method use might be expected to have based their rationale on prior experience using modern contraceptives. We compare the level of prior modern method use among women who cite these reasons with the level among women who cite other reasons for nonuse in many countries. In 32 of the 48 countries for which data are available, women who cite concerns regarding side effects and health risks are significantly more likely to have used a modern method in the past than are women who cite other reasons for nonuse. Twenty-three of these countries are in sub-Saharan Africa.

Breastfeeding is considered an effective form of contraception up to six months postpartum if a woman is exclusively breastfeeding (Consensus Statement 1988). In 43 countries, fewer than half of women who cite postpartum amenorrhea or breastfeeding as reasons for nonuse had given birth in the prior six months and reported elsewhere that they are amenorrheic (see Table 4). At the national level, among women who offer these reasons for nonuse, the proportion reporting that they are amenorrheic and had given birth within six months ranges from 2 percent (Kyrgyz Republic) to 74 percent (Peru). We could not compute the proportions of women who are exclusively breastfeeding because women are not asked this question in the survey.

\section{DISCUSSION}

Policymakers, donor agencies, and social scientists rely on estimates of levels of unmet need for contraception to help make the case for policy and program interventions. Such policy and program actions can also benefit from information regarding the barriers faced by women having unmet need and how these barriers vary across populations. Information from the present review, taken together with findings from qualitative studies that explore in greater depth women's reasons for nonuse in specific geographic areas and populations, can help provide 
TABLE 4 Percentage of women reporting recent sexual activity, prior contraceptive use, and reported time of most recent birth and amenorrheic status, by country, according to subgroups of married women having unmet need, 51 developing countries, 2006-13

\begin{tabular}{|c|c|c|c|c|c|}
\hline \multirow[b]{2}{*}{ Region/country } & \multicolumn{2}{|c|}{$\begin{array}{l}\text { Women who had sex } \\
\text { in prior three months }\end{array}$} & \multicolumn{2}{|c|}{$\begin{array}{l}\text { Women who used } \\
\text { a modern method } \\
\text { in the past }\end{array}$} & \multirow{2}{*}{$\begin{array}{r}\text { Women who } \\
\text { gave birth } \\
\text { in preceding } \\
6 \text { months and } \\
\text { reported being } \\
\text { amenorrheic, } \\
\text { among those } \\
\text { who cite } \\
\text { postpartum } \\
\text { amenorrhea/ } \\
\text { breastfeeding }\end{array}$} \\
\hline & $\begin{array}{r}\text { Among those } \\
\text { who cite } \\
\text { infrequent sex }\end{array}$ & $\begin{array}{c}\text { Among all } \\
\text { others with } \\
\text { unmet need }\end{array}$ & $\begin{array}{r}\text { Among those } \\
\text { who cite } \\
\text { side effects/ } \\
\text { health risks }\end{array}$ & $\begin{array}{c}\text { Among all } \\
\text { others with } \\
\text { unmet need }\end{array}$ & \\
\hline \multicolumn{6}{|l|}{ Latin America and Caribbean } \\
\hline Bolivia & 46.7 & $87.1^{* * *}$ & 40.5 & 42.1 & 59.4 \\
\hline Colombia & 55.0 & $93.8^{\star * *}$ & 89.3 & 89.2 & 71.6 \\
\hline Dominican Republic & 54.8 & $96.8^{\star * *}$ & 85.6 & $75.0^{* * *}$ & 50.5 \\
\hline Guyana & 49.2 & $88.6^{* * *}$ & 74.0 & 74.6 & 43.3 \\
\hline Haiti & 50.4 & $90.1^{\star * *}$ & 57.9 & $47.0^{* * *}$ & 41.4 \\
\hline Honduras & 31.7 & $93.8^{\star * *}$ & 87.8 & 84.8 & 55.7 \\
\hline Peru & 50.9 & $76.7^{* * *}$ & 80.4 & 80.8 & 74.1 \\
\hline \multicolumn{6}{|l|}{ Asia } \\
\hline Armenia & 22.1 & $93.8^{\star * \star}$ & 48.1 & $76.8^{\star *}$ & 12.9 \\
\hline Azerbaijan & 59.5 & $94.8^{* * *}$ & 45.3 & 38.5 & 31.0 \\
\hline Bangladesh & 35.1 & $93.1^{* * *}$ & 79.9 & 78.1 & 47.8 \\
\hline Cambodia & 83.6 & $94.9^{* * *}$ & na & na & 21.3 \\
\hline India & 58.9 & $87.3^{* * *}$ & 31.2 & $23.6^{* * *}$ & 25.9 \\
\hline Indonesia & 57.7 & $88.5^{\star * *}$ & 85.1 & $82.6^{*}$ & 35.4 \\
\hline Kyrgyz Republic & 39.1 & $93.0^{* * *}$ & 47.8 & 41.8 & 1.9 \\
\hline Jordan & 38.3 & $95.6^{\star * *}$ & 81.8 & 81.8 & 52.8 \\
\hline Nepal & 36.7 & $93.1^{* * *}$ & 71.0 & $61.3^{* *}$ & 50.2 \\
\hline Pakistan & 56.3 & $90.6^{* * *}$ & 53.6 & 49.5 & 21.6 \\
\hline Philippines & 47.1 & $88.6^{\star * *}$ & 53.4 & 55.1 & 55.7 \\
\hline Tajikistan & 40.5 & $85.0^{* * *}$ & 48.8 & $27.8^{\star * *}$ & 2.7 \\
\hline Timor-Leste & 81.1 & $92.7^{\star \star}$ & 20.4 & $12.0^{\star * *}$ & 22.9 \\
\hline \multicolumn{6}{|l|}{ Africa } \\
\hline Benin & 37.5 & $73.0^{* * *}$ & 31.0 & $17.2^{\star * *}$ & 27.7 \\
\hline Burkina Faso & 43.0 & $78.4^{* * *}$ & 30.9 & $10.4^{* * *}$ & 8.6 \\
\hline Burundi & 59.6 & $97.9^{\star * *}$ & 27.3 & $10.4^{* * *}$ & 31.1 \\
\hline Cameroon & 38.3 & $81.3^{* * *}$ & 34.1 & $43.0^{* *}$ & 26.1 \\
\hline Côte d'Ivoire & 47.3 & $80.6^{* * *}$ & 24.4 & 25.8 & 24.9 \\
\hline Congo (Brazzaville) & 44.8 & $81.3^{\star \star *}$ & 37.3 & $46.2^{*}$ & 37.9 \\
\hline Democratic Republic of Congo & 56.7 & $76.8^{* * *}$ & 19.1 & $12.9^{\star *}$ & 35.8 \\
\hline Egypt & na & na & 85.8 & $73.0^{* * *}$ & 31.6 \\
\hline Ethiopia & 38.2 & $91.1^{* * *}$ & 37.2 & $24.1^{* * *}$ & 35.8 \\
\hline Gabon & 63.2 & $75.7^{\star *}$ & 34.5 & $43.2^{*}$ & 44.9 \\
\hline Ghana & 35.0 & $70.4^{* * *}$ & 44.4 & 43.3 & 26.6 \\
\hline Guinea & 29.9 & $42.5^{\star *}$ & 21.9 & $12.2^{* *}$ & 7.8 \\
\hline Kenya & 47.8 & $88.1^{\star * \star}$ & 65.4 & $50.2^{\star * \star}$ & 46.2 \\
\hline Lesotho & 49.0 & $69.3^{* * *}$ & 63.3 & 59.4 & 43.4 \\
\hline Liberia & 40.6 & $71.8^{\star * *}$ & 37.9 & $29.1^{\star *}$ & 21.6 \\
\hline Madagascar & 68.8 & $92.2^{* * *}$ & 41.8 & $30.3^{* * *}$ & 32.9 \\
\hline Malawi & 36.8 & $84.2^{* * *}$ & 62.4 & $65.9^{*}$ & 40.4 \\
\hline Mali & 52.7 & $89.7^{* * *}$ & 25.2 & $15.6^{* * *}$ & 20.3 \\
\hline Mozambique & 61.6 & $78.8^{* * *}$ & na & na & 12.5 \\
\hline Namibia & 34.2 & $80.2^{\star * *}$ & 85.9 & $69.3^{\star * *}$ & 27.0 \\
\hline Niger & 37.2 & $92.3^{* * *}$ & 34.1 & $23.8^{* * *}$ & 21.5 \\
\hline Nigeria & 50.7 & $82.9^{* \star *}$ & 28.1 & $21.8^{\star * *}$ & 19.7 \\
\hline Rwanda & 40.8 & $98.4^{* * *}$ & 43.1 & $31.3^{* * *}$ & 41.5 \\
\hline
\end{tabular}




\begin{tabular}{|c|c|c|c|c|c|}
\hline \multirow[b]{2}{*}{ Region/country } & \multicolumn{2}{|c|}{$\begin{array}{l}\text { Women who had sex } \\
\text { in prior three months }\end{array}$} & \multicolumn{2}{|c|}{$\begin{array}{l}\text { Women who used } \\
\text { a modern method } \\
\text { in the past }\end{array}$} & \multirow{2}{*}{$\begin{array}{r}\text { Women who } \\
\text { gave birth } \\
\text { in preceding } \\
6 \text { months and } \\
\text { reported being } \\
\text { amenorrheic, } \\
\text { among those } \\
\text { who cite } \\
\text { postpartum } \\
\text { amenorrhea/ } \\
\text { breastfeeding }\end{array}$} \\
\hline & $\begin{array}{r}\text { Among those } \\
\text { who cite } \\
\text { infrequent sex }\end{array}$ & $\begin{array}{c}\text { Among all } \\
\text { others with } \\
\text { unmet need }\end{array}$ & $\begin{array}{r}\text { Among those } \\
\text { who cite } \\
\text { side effects/ } \\
\text { health risks }^{b}\end{array}$ & $\begin{array}{l}\text { Among all } \\
\text { others with } \\
\text { unmet need }\end{array}$ & \\
\hline Sao Tome and Principe & 57.7 & $94.2^{\star * \star}$ & 79.0 & $65.5^{\star *}$ & 44.4 \\
\hline Senegal & 46.1 & $86.0^{* * *}$ & 37.0 & $24.1^{* * *}$ & 20.7 \\
\hline Sierra Leone & 13.9 & $47.5^{* * *}$ & 27.2 & $18.4^{* *}$ & 18.0 \\
\hline Swaziland & 51.1 & $88.5^{\star * \star}$ & 86.3 & 82.3 & 37.2 \\
\hline Tanzania & 45.2 & $86.8^{* * *}$ & na & na & 37.4 \\
\hline Uganda & 58.9 & $88.3^{* * *}$ & 47.5 & $38.0^{* *}$ & 42.8 \\
\hline Zambia & 62.8 & $85.2^{\star * \star}$ & 64.8 & 60.0 & 43.4 \\
\hline Zimbabwe & 48.2 & $86.3^{* * *}$ & 87.5 & $71.0^{* *}$ & 36.6 \\
\hline
\end{tabular}

the empirical basis for relevant investments in policy action and programmatic responses.

Recent studies have estimated the level of unmet need for any method (modern or traditional) of contraception among married women (Alkema et al. 2013) and the level of unmet need for a modern method among all (married and unmarried) women (Darroch, Singh, and Ashford 2013). The regional estimates published by both Alkema and colleagues (2013) and Darroch, Singh, and Ashford (2013) seem lower than those presented here. ${ }^{6}$ Both of those studies used a larger evidence base than was used here, because we limited ourselves to surveys having information regarding levels of unmet need and women's reasons for contraceptive nonuse.

We found that infrequent sexual activity and concerns regarding the side effects and health risks associated with contraceptive methods are the most common reasons for nonuse in many developing countries. Comparisons with findings from Demographic and Health Surveys conducted in 1995-2005 (Sedgh et al. 2007) indicate that infrequent sex has become a substantially more common reason for nonuse in all Asian countries having trend data-except for Armenia-in recent years. Labor migration might be contributing to this phenomenon (Overseas Development Institute 2006; Sidiqui 2008). It could be the case that other potential obstacles to contraceptive use have been resolved for a substantial share of the population, and much of the remaining pool of women having unmet need consists of those who in fact are at relatively low risk (though not necessarily without risk) of unintended pregnancy.

Access barriers are cited infrequently in most countries. The fact that these barriers are cited even less frequently in current surveys than in 1995-2005 in most countries, whereas concerns regarding side effects are becoming more prevalent (see Sedgh et al. 2007 for the findings for the 1995-2005 period), suggests that contraceptive supplies are becoming increas-

6 If estimates published by Darroch, Singh, and Ashford (2013) excluded users of traditional methods from the counts of women having unmet need, their estimates would likely be lower than those presented here. 
ingly accessible and that counseling regarding contraceptive options is a critical component of effective service provision.

This analysis has some important limitations. The Latin America and Caribbean region is not well represented by the data, and inferences cannot be made for the region on the basis of the country-specific findings. The level of unmet need might be lower in the countries in this region that are no longer deemed to need a Demographic and Health Survey than in the countries included in the current analysis. Nevertheless, the findings presented here suggest that the level of unmet need in several countries in the region still call for attention. Also, Asia is an exceptionally large and heterogeneous region, and regional averages do not necessarily reflect findings for particular countries or subregions. Subregional findings for South-Central and South-Eastern Asia are provided and should more closely reflect findings for the countries they encompass, but Eastern Asia is not represented and Western Asia is poorly represented by the surveys.

Differences in the ranking of key reasons for nonuse of contraceptives across population subgroups of women-defined, for example, by poverty status of urban or rural place of residence-could also provide valuable information to stakeholders who are seeking to design appropriate interventions for their target populations.

Understanding barriers to contraceptive use faced by unmarried women is also critical. The breadth of information regarding unmarried women is more limited because some national surveys do not include this population in their samples, and some surveys do not ask unmarried women the questions necessary to ascertain the level of need for contraception and reasons for contraceptive nonuse. Thus, estimation of regional and subregional variations on the experiences of unmarried women might not be tenable. Nevertheless, further analysis of unmarried women's unmet need and reasons for contraceptive nonuse is critical.

Many women having unmet need have practiced contraception in the past. Studies of the challenges that threaten continued use of a method could help program planners support sustained use of methods among women who have discontinued in the past. Research exploring providers' perspectives concerning obstacles to satisfying unmet need for contraception and preventing discontinuation by women in need is also needed.

As noted, most women gave only one reason for nonuse, whereas many women likely contend with multiple barriers to contraceptive use. Women's stated reasons for nonuse might reflect the reasons they are most comfortable stating, or the most immediate or pressing obstacles to contraceptive use. Qualitative research investigating women's experiences and indepth quantitative studies could substantially improve our ability to understand the barriers they face and how to help them overcome these barriers. Such research could help us better understand the reasons given, such as the nature of women's or partners' opposition and the specific side effects and health risks that most concern them.

Among women classified as having unmet need, a range in intensity of need likely exists. For example, some women who report that they are not using a method because they are infrequently sexually active are likely to have a low frequency of intercourse and thus a low level of risk of unintended pregnancy. Also, women who are classified as having unmet need because they are not sure whether or when they want to have a(nother) child might be less distraught by a pregnancy than women having a more definitive wish to avoid or delay a pregnancy. 
Some of the reasons for nonuse examined in this study are broad and can encompass a number of more specific reasons. Surveyed women are not probed for further detail concerning their chosen reason for nonuse. A few possible interpretations of their reasons are elucidated below. Additional research can help enhance the picture by identifying detailed reasons that are most prevalent.

\section{Underlying Reasons for Nonuse of Contraception}

\section{Postpartum Amenorrhea or Breastfeeding}

A woman who cites one or both of these reasons for nonuse could think her probability of becoming pregnant is minimal, or could be afraid that a hormonal method might negatively affect her breast milk or her own health. Or her reasons might be more cultural in nature: the norm in her society might be to abstain from having sex during this period of time, and she may not want to use a method even if she is sexually active because she is expected to be sexually inactive.

\section{Lack of Awareness of Contraception}

Women who indicated that they do not know about contraceptive methods could feel that they need to know more about specific methods of contraception before using one, or they could lack awareness of the concept of fertility control.

\section{Opposition to Contraception}

Opposition can stem from a woman's or her partner's personal or religious beliefs. Some individuals might be opposed to contraception because of concerns regarding side effects and health risks, which they did not express to the interviewer. Thus, this broad umbrella could include barriers that reflect cultural norms and beliefs, and barriers that could be reduced through effective programmatic responses. Some women who are opposed may have partners who are also opposed, and women might not have cited their own opposition in the survey once they had reported their partners' opposition.

\section{Fear of Side Effects or Health Risks and Inconvenience of Use}

Women who cite reasons related to use of the methods might base their reasoning on their personal experience, on the experiences of women they know, or simply on their perceptions regarding contraception. These women's concerns might be based on misinformation or on a fairly accurate appraisal of side effects and health risks.

Other research has shown that concerns regarding side effects and health risks are among the most common reasons for discontinuing the practice of contraception among women who continue to have a need for contraception (Bradley, Schwandt, and Kahn 2009). Concerns regarding side effects and health risks are especially common among women who have previously used injectables, IUDs, and oral contraceptives (Lee and Jezewski 2007; Bradley, Schwandt, and Kahn 2009). Further large-scale research is needed to ascertain the specific side effects and health risks - whether real or perceived - that prevent women from using a method. 


\section{Subfecundity}

Women who appear to be subfecund (e.g,, who have been married for at least five years, have not used a method, and have not become pregnant) are not classified by the DHS as having unmet need and are not asked their reason for nonuse. Women who report that they are not using a method because they are subfecund may or may not be providing an accurate assessment of their risk of becoming pregnant. In a US sample, 36 percent of women who were not using a contraceptive method when they had an unintended pregnancy indicated that they were not using a method because they did not think they could become pregnant (Mosher 2012). Though these women's reasons for thinking they would not become pregnant could extend beyond subfecundity, this finding suggests that at least some women who believe they are infecund are incorrect.

\section{CONCLUSION}

Despite the limitations in our ability to interpret women's reported reasons for contraceptive nonuse, these surveys elucidate the key barriers experienced by women, even if in general terms. Taken together they provide a valuable picture of the remaining gaps in efforts to help satisfy unmet need for contraception. The evidence presented here makes clear that access to contraceptive supplies is not sufficient as a means to satisfy unmet need for contraception. The high prevalence of concerns regarding side effects and health risks among women having unmet need likely reflects a need for: information and counseling to help women learn more about the methods available to them, better mechanisms through which women can switch methods when needed, and an expansion of method choices. Many women who cite infrequent sex or postpartum amenorrhea or breastfeeding would benefit from counseling regarding their risk of pregnancy and the methods that are appropriate for their circumstances. Counseling and services provided for antenatal care and at the point of delivery might be especially appropriate for women who perceive that they are at low risk of becoming pregnant during the postpartum period. Although access to services does not appear to be the main barrier to effective contraceptive use, access to services that provide a range of methods from which to choose and also provide information and counseling to help women select and effectively use an appropriate method can be critical to helping women having unmet need overcome obstacles to contraceptive use.

As noted by Casterline and Sinding (2000), the extent to which programmatic interventions can serve women having unmet need for contraception depends on the nature of women's reasons for nonuse. Improvements in the quality of programs and services can go a long way toward addressing many of the concerns identified in this study. Such improvements can potentially even affect social and cultural opposition to family planning. Expansion of educational and economic opportunities for women over the long term can also affect the attitudes of women and their partners and community values regarding the feasibility and benefits of fertility control.

Further research could contribute to effective decisionmaking and allocation of resources intended to satisfy unmet need for contraception. Such research should include analysis of levels of unmet need and reasons for nonuse among never-married women; differences in 
reasons for nonuse across population subgroups; problems faced by contraceptive users; and providers' perspectives regarding barriers to effective contraceptive use. Studies that explore some of the commonly cited challenges to contraceptive use in greater depth while also reaching broad populations, ideally through a hybrid of qualitative and quantitative research, could provide invaluable information to stakeholders.

International family planning efforts have made important inroads in satisfying demand for contraception; however, millions of women worldwide still have unintended pregnancies each year (Singh et al. 2010; Sedgh et al. 2013). Continued efforts are needed and can have a tremendous impact on the ability of women and couples to avoid unintended pregnancies and achieve their fertility goals, and on the health and well-being of women, their families, and society.

\section{REFERENCES}

Alkema, Leontine, Vladimira Kantorova, Clare Menozzi, and Ann Biddlecom. 2013. "National, regional, and global rates and trends in contraceptive prevalence and unmet need for family planning between 1990 and 2015: A systematic and comprehensive analysis," The Lancet 381(9878): 1642-1652.

Bongaarts, John and Judith Bruce. 1995. "The causes of unmet need for contraception and the social content of services," Studies in Family Planning 26(2): 57-75.

Bradley, Sarah E.K., Trevor N. Croft, Joy D. Fishel, and Charles F. Westoff. 2012. "Revising unmet need for family planning." DHS Analytical Studies No. 25. Calverton, MD: ICF International.

Bradley, Sarah, Hilary Schwandt, and Shane Kahn. 2009. "Levels, trends, and reasons for contraceptive discontinuation." DHS Analytical Studies No. 20. Calverton, MD: ICF International.

Campbell, Martha, Nuriye Nalan Sahin-Hodoglugil, and Malcolm Potts. 2006. "Barriers to fertility regulation: A review of the literature," Studies in Family Planning 37(2): 87-98.

Casterline, John B., Aurora E. Perez, and Ann E. Biddlecom. 1997. "Factors underlying unmet need for family planning in the Philippines," Studies in Family Planning 28(3): 173-191.

Casterline, John B., Zeba A. Sathar, and Minhaj ul Haque. 2001. "Obstacles to contraceptive use in Pakistan: A study in Punjab," Studies in Family Planning 32(2): 95-110.

Casterline, John B. and Steven W. Sinding. 2000. "Unmet need for family planning in developing countries and implications for population policy," Population and Development Review 26(4): 691-723.

Consensus Statement. 1988. "Breastfeeding as a family planning method," The Lancet 2(8621): 1204-1205.

Darroch, Jacqueline E., Gilda Sedgh, and Haley Ball. 2011. “Contraceptive technologies: Responding to women's needs.” New York: Guttmacher Institute.

Darroch, Jacqueline E., Susheela Singh, and Lori S. Ashford. 2013. "Adding it up: The need for and cost of maternal and newborn care-Estimates for 2012.” New York: Guttmacher Institute.

Lee, Jongwon and Mary Ann Jezewski. 2007. "Attitudes toward oral contraceptive use among women of reproductive age: A systematic review,” Advances in Nursing Science 30(1): E85-E103.

Mosher, William D., Jo Jones, Joyce C. Abma. 2012. “Intended and unintended births in the United States: 1982-2010.” National Health Statistics Report No. 55. Hyattsville, MD: National Center for Health Statistics.

Overseas Development Institute. 2006. “Internal migration, poverty and development in Asia.” London.

Sedgh, Gilda, Rubina Hussain, Akinrinola Bankole, and Susheela Singh. 2007. "Women with an unmet need for contraception in developing countries and their reasons for not using a method." New York: Guttmacher Institute.

Sedgh, Gilda, Susheela Singh, Rubina Hussain, and Michelle Eilers. 2013. "Incidence of unintended pregnancies worldwide in 2012 and trends since 1995." Paper presented at the Annual Meeting of the Population Association of America, New Orleans, LA, 11-13 April. 
Sidiqui, Tasneem. 2008. "Migration and gender in Asia." Paper presented at the United Nations Expert Group Meeting on International Migration and Development in Asia and the Pacific, Economic and Social Commission for Asia and the Pacific, Population Division, Bangkok, 20-21 September.

Singh, Susheela and Jacqueline Darroch. 2012. “Adding It Up: Costs and Benefits of Contraceptive Services-Estimates for 2012. New York: Guttmacher Institute and United Nations Population Fund (UNFPA).

Singh, Susheela, Gilda Sedgh, and Rubina Hussain. 2010. "Unintended pregnancy: Worldwide levels, trends, and outcomes," Studies in Family Planning 41(4): 241-250.

Stash, Sharon. 1999. "Explanations of unmet need for contraception in Chitwan, Nepal," Studies in Family Planning 30(4): 267-287.

United Nations (UN), Department of Economic and Social Affairs, Population Division. 2013a. World Population Prospects, 2012 Revision. CD-ROM edition. New York.

—. 2013b. World Marriage Data 2012 (POP/DB/Marr/Rev2012). New York.

Westoff, Charles F. and Akinrinola Bankole. 1995. "Unmet need: 1990-1994.” DHS Comparative Studies No. 16. Calverton, MD: Macro International.

Williamson, Lisa M., Alison Parkes, Daniel Wight, Mark Petticrew, and Graham J. Hart. 2009. "Limits to modern contraceptive use among young women in developing countries: A systematic review of qualitative research," Reproductive Health 6(3): 1-12.

\section{ACKNOWLEDGMENTS}

The authors would like to thank Iqbal Shah and Akinrinola Bankole for reviewing earlier drafts of the manuscript, and Michelle Eilers for her research assistance. 